\title{
Diagnosis of giant cell arteritis
}

\author{
Cristina Ponte ${ }^{1,2}$, Joana Martins-Martinho ${ }^{1}$ and Raashid Ahmed Luqmani ${ }^{3}$
}

\begin{abstract}
GCA is the most common form of primary systemic vasculitis affecting older people. It is considered a clinical emergency because it can lead to irreversible blindness in around $20 \%$ of untreated cases. High doses of glucocorticoids should be initiated promptly to prevent disease-related complications; however, glucocorticoids therapy usually results in significant toxicity. Therefore, correct diagnosis is crucial. For many years, temporal artery biopsy has been considered the diagnostic 'gold standard' for GCA, but it has many limitations (including low sensitivity). US has proven to be effective for diagnosing GCA and can reliably replace temporal artery biopsy in particular clinical settings. In cases of suspected GCA with large-vessel involvement, other imaging modalities can be used for diagnosis (e.g. CT and PET). Here we review the current evidence for each diagnostic modality and propose an algorithm to diagnose cranial-GCA in a setting with rapid access to high quality US.
\end{abstract}

Key words: giant cell arteritis, diagnosis, temporal artery biopsy, ultrasound, magnetic resonance, computed tomography, positron emission tomography, imaging

\section{Rheumatology key messages}

- Correct, early diagnosis of GCA avoids overtreatment and prevents disease-related complications.

- In an appropriate clinical setting, US can replace temporal artery biopsy to diagnose GCA.

- In cases of suspected large-vessel GCA, CT, MRI and PET-CT can be used for diagnosis.

\section{Introduction}

GCA is the most common form of primary systemic vasculitis in patients aged $>50$ years. It occurs predominantly in the northern latitudes, mainly affecting Caucasians, with an overall annual incidence of 15-25 per 100000 individuals older than 50 years [1]. Its incidence increases with age, peaking between $70-80$ years, and it is more common in women than men, in a 2-4:1 proportion [2, 3].

The vasculitic process in GCA affects large- and medium-sized blood vessels with predisposition for the involvement of cranial arteries derived from the carotid artery [4]. Due to the intense myointimal proliferation and vessel occlusion, major ischaemic events may occur in this disease, such as arteritic anterior ischaemic optic

${ }^{1}$ Rheumatology Department, Hospital de Santa Maria - Centro Hospitalar Universitário Lisboa Norte, Centro Académico de Medicina de Lisboa, Lisbon, ${ }^{2}$ Unidade de Investigação em Reumatologia, Instituto de Medicina Molecular, Faculdade de Medicina, Universidade de Lisboa, Lisbon, Portugal and ${ }^{3}$ Nuffield Department of Orthopaedics, Rheumatology and Musculoskeletal Sciences, University of Oxford, Oxford, UK

Submitted 3 September 2019; accepted 15 October 2019

Correspondence to: Cristina Ponte, Rheumatology Department, Hospital de Santa Maria - CHULN, Av. Prof. Egas Moniz, 649-035 Lisboa, Portugal. E-mail: cristinadbponte@gmail.com neuropathy, which can result in irreversible blindness. Treatment with high doses of glucocorticoids (GCs) should be initiated as early as possible to rapidly control disease manifestations and prevent complications. However, GC therapy may cause various adverse effects, previously reported in over $80 \%$ of patients [5], particularly in the period shortly following GC initiation [6]. Therefore, the need for a correct diagnosis is essential in GCA.

Here we will review the clinical features that should raise suspicion for GCA, current diagnostic modalities [temporal artery biopsy (TAB), US and other imaging techniques]), and diagnostic and classification criteria, and propose a diagnostic approach to patients with suspected GCA.

\section{Clinical manifestations}

The most frequent symptoms and signs of GCA are related to the disease involvement of cranial arteries, predominantly the temporal artery. New onset of headache, particularly in the temporal region, is the most common symptom of the disease [7], and jaw claudication is the most specific manifestation [8]. Scalp tenderness and visual disturbances can also be present; scalp necrosis and tongue claudication or necrosis occur less 
FIG. 1 Swollen right temporal artery (frontal branch) of a patient with GCA

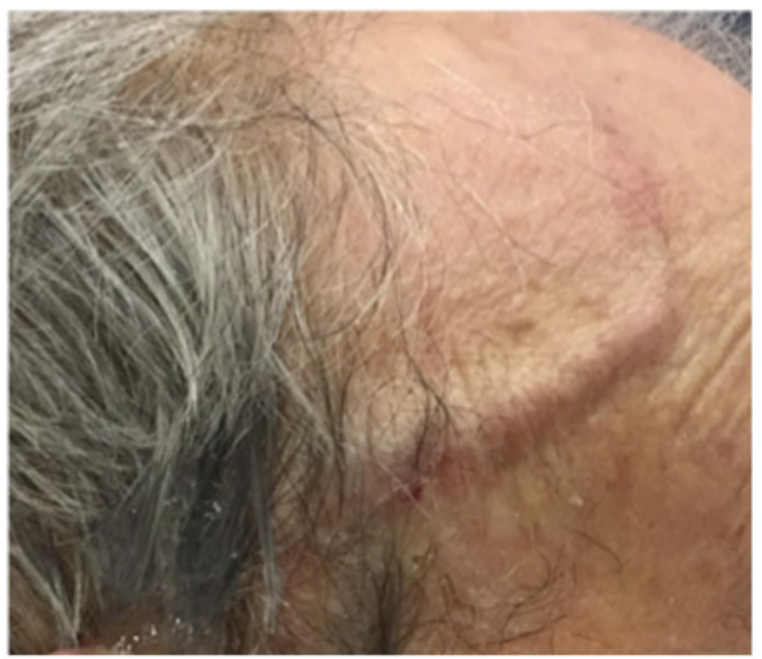

commonly. On physical examination, temporal arteries may be tender or thickened on palpation, and pulses diminished or absent (Fig. 1). GCA-related severe cranial ischaemic events include blindness, which can occur in $\sim 15-20 \%$ of patients, often secondary to anterior ischaemic optic neuropathy [9, 10], and cerebrovascular accidents (transient ischaemic attack or stroke) present in $3-7 \%$ of cases [11-13]. Given that these serious events may frequently occur at disease onset, GCA is considered to be a medical emergency [14]. Patients with a suspected diagnosis of cranial GCA should be immediately referred for specialist care, but the initiation of treatment should not be delayed by diagnostic procedures such as TAB or imaging [15].

Extra-cranial involvement in GCA affecting the aorta and its major branches, also known as large-vessel GCA (LV-GCA), has been described in $20-80 \%$ of cases, depending upon the imaging modality used for screening the disease [16-18]. These patients can be either asymptomatic or present with limb claudication, vascular bruits and decreased or absent pulses [19]. Late potential complications include valvular heart disease and aortic aneurysms and/or dissections [20-22].

Although very non-specific, systemic symptoms such as fatigue, low-grade fever and weight loss are often present in patients with a diagnosis of GCA. In addition, PMR, characterized by pain and morning stiffness particularly in the shoulders and hips, occurs in about $40-60 \%$ of patients with GCA, and $16-21 \%$ of patients with the diagnosis of PMR have, or will develop, GCA [23].

High levels of inflammatory markers are present in the majority of patients with GCA at disease presentation. However, in cases of localized disease, without constitutional symptoms, ESR and CRP values may be within the normal range, and this subgroup of patients are
TABLE 1 Clinical and laboratory features of GCA

\begin{tabular}{lc}
\hline Clinical feature & Frequency (\%) \\
\hline Elevated ESR and/or elevated CRP & $90-95$ \\
Headache & $70-90$ \\
Audiovestibular manifestations (hearing & Up to 90 \\
$\quad$ loss, tinnitus, vertigo, abnormal & \\
vestibular testing, etc.) & \\
PMR & $40-60$ \\
Constitutional symptoms (low-grade & $30-60$ \\
$\quad$ fever, fatigue or weight loss) & \\
Abnormal temporal artery on physical & $30-60$ \\
$\quad$ examination (tenderness, or absent or & \\
$\quad$ diminished pulses) & \\
Jaw claudication & $40-50$ \\
Scalp tenderness & $33-50$ \\
Visual disturbances (transient or & $20-50$ \\
$\quad$ permanent) & \\
Visual loss due to ${ }^{\text {b }}$ & \\
$\quad$ Anterior ischaemic optic neuropathy & 91 \\
$\quad$ Central retinal artery occlusion & 11 \\
$\quad$ Cilioretinal artery occlusion & 10 \\
$\quad$ Posterior ischaemic optic neuropathy & 4 \\
Respiratory symptoms (cough, sore & $\sim 10$ \\
$\quad$ throat or hoarseness) & \\
Cerebrovascular accidents (transient & $3-7$ \\
ischemic attack or stroke) & \\
Scalp necrosis & $<5$ \\
Tongue necrosis & $<5$ \\
&
\end{tabular}

${ }^{a}$ Based on a study from Amor-Dorado et al. 2003 [27].

${ }^{b}$ Based on a study from Hayreh et al. 2002 [28].

known to be at higher risk of developing ocular ischaemic complications [24-26].

A summary of the clinical features and frequencies in which they occur in GCA can be found in Table 1 .

\section{Temporal artery biopsy}

GCA was historically believed to be confined to the cranial arteries; therefore, for many years, TAB was considered to be the diagnostic 'gold standard'. TAB should be performed by an experienced surgeon, in order to obtain good quality biopsy samples, and preferably within the first 7 days of treatment initiation, in order to enhance its sensitivity [29]. The optimal length of the biopsy specimen remains debatable. Segments of at least $0.5-1 \mathrm{~cm}$ post-formalin fixation are considered acceptable in various studies [29-32]. In practical terms, this requires harvesting biopsies around $1.5 \mathrm{~cm}$ in length to allow for an estimated $10 \%$ tissue shrinkage during fixation [33]. TAB should be obtained from the most symptomatic site; US guidance in TAB has failed to show improvement in the sensitivity for diagnosing GCA [34]. Moreover, biopsy of the contralateral artery has been reported to only increase the diagnostic yield by $4-13 \%$ [35-39] and is therefore not routinely recommended.

$T A B$ has the advantage of aiding correct differential diagnosis between GCA and other diseases (e.g. 
ANCA-associated vasculitis, amyloidosis, etc.). In addition, distinct histopathological features of TAB have been associated with different clinical manifestations of the disease, suggesting a potential prognostic value for this diagnostic method [40-43]. The classic histological picture of GCA is a transmural inflammatory infiltrate associated with marked disruption of the internal elastic lamina and the presence of giant cells. However, TAB may contain less obvious characteristics of the disease, such as periadventitial/vasa vasorum restricted inflammation or intimal hyperplasia, which make the histologic diagnosis less straightforward [44-46]. An inter-rater analysis for biopsy results was conducted in the multicentre TABUL (Temporal Artery Biopsy vs ULtrasound in diagnosis of GCA) study, revealing a large amount of variability in agreement between pathologists. A total of 30 cases were reviewed by 14 pathologists and only in 11 cases did all pathologists agree on the results (consistent vs not consistent with GCA), which corresponded to an intra-class correlation coefficient of $0.62(95 \% \mathrm{Cl}$ $0.49,0.76$ ) [29]. Thus, it is vital to interpret $T A B$ results with caution, and to establish good communication between clinicians and pathologists.

Despite the high specificity of TAB for diagnosing GCA (up to $100 \%$ ), sensitivity can be as low as $39 \%$ mainly due to poor sampling (it is estimated that around $7 \%$ of all TABs may not actually consist of arterial tissue [29]); reduced accessibility to the procedure; the segmented nature of the pathological findings, also described as 'skip lesions' [47]; and the presence of LVGCA, which is known to have less temporal arterial involvement of the disease [48]. In addition, although TAB is regarded as a generally safe procedure, it is still an invasive technique with an associated complication rate of $\sim 0.5 \%$ [49], with the most serious complications reported including facial nerve injury [50-55] and scalp necrosis [56]. Therefore, less invasive options with higher sensitivity for diagnosis could improve patient care in GCA.

\section{Imaging}

\section{Ultrasound}

In 1997, Schmidt et al. described for the first time the importance of temporal artery US in the diagnosis of GCA, based on the presence of a homogeneous, hypoechoic wall thickening, known as the 'halo sign' (Fig. 2) $[57,58]$. Stenoses and occlusions, although less specific for GCA, may also be found in patients with this diagnosis. More recently, incompressibility of the temporal artery upon application of pressure with the US probe, termed as the 'compression sign', has been reported to have a positive predictive value of $100 \%$ for GCA diagnosis $[59,60]$. Many studies, particularly in the past two decades, have investigated the diagnostic accuracy of various US findings in GCA [61]. Table 2 summarizes the results of five meta-analyses that have addressed this issue so far [3,62-65], in which US yields an overall
FIG. 2 US of a patient with GCA showing a 'halo sign' in the temporal artery

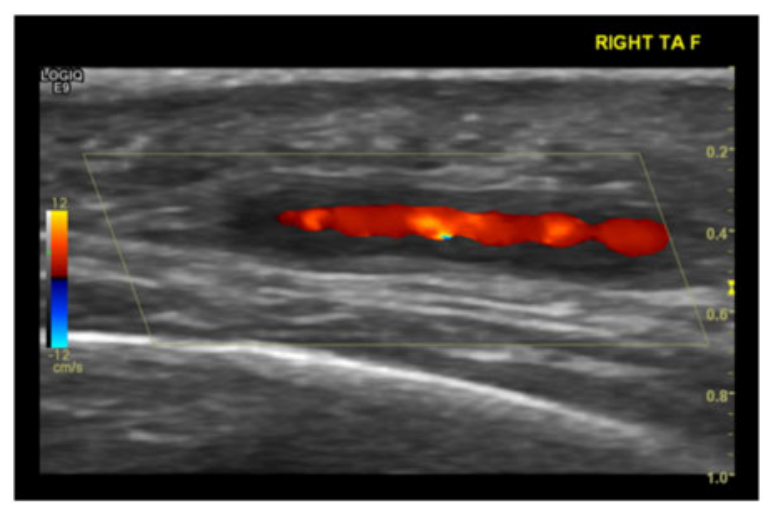

sensitivity of $68-88 \%$ and specificity of $77-91 \%$, in comparison with TAB, for the diagnosis of GCA. The TABUL study assessed the diagnostic accuracy and costeffectiveness of $U S$ and $T A B$ in a prospective multicentre cohort study, using a clinical diagnosis as reference standard [29]. A total of 381 patients underwent both US and TAB in the first 10 days of commencing high doses of GCs ( $>20 \mathrm{mg}$ of prednisolone or equivalent per day). US showed a sensitivity of $54 \%$ and specificity of $81 \%$ for GCA diagnosis, whereas TAB had a sensitivity of $39 \%$ and specificity of $100 \%$. Of note, TAB was part of the reference standard, thus the $100 \%$ specificity might have been heavily influenced by study methodology. A combination strategy using both modalities in sequence, with all patients undergoing US, but only performing $\mathrm{TAB}$ in negative cases, increased the sensitivity to $65 \%$ and maintained specificity at $81 \%$ (decreasing the need for TAB by $43 \%$ ). However, the best and most cost-effective diagnostic strategy, with an incremental net monetary benefit of $£ 485$ per patient, consisted of further combination with clinical judgement. Only in cases of high clinical suspicion, but a negative US, should TAB be considered, leading to a sensitivity of $93 \%$ and specificity of $77 \%$.

US should be performed with high quality equipment, by experienced ultrasonographers, and in a timely manner $[15,66]$. Most modern US machines are able to provide a resolution of $0.1 \mathrm{~mm}$ and thus are very sensitive to detect the halo sign, which is estimated to measure $>0.29-0.42 \mathrm{~mm}$ in the temporal arteries and $>1.0 \mathrm{~mm}$ in the axillary arteries [67]. The halo sign and compression sign have been regarded by the OMERACT Large Vessel Vasculitis Ultrasound Working Group as the most important US findings suggestive of vasculitis, and the presence of the halo sign to be a minimum requirement to diagnose GCA [58]. In addition, detection of the halo sign rapidly diminishes following treatment [68] and it has been reported to disappear after a mean of 210 weeks [57, 69-71]; therefore, US should be performed as early as possible after symptom onset. Two retrospective studies have shown that a fast-track 
TABLE 2 Results of five meta-analyses assessing the performance characteristics of US abnormalities to diagnose GCA

\begin{tabular}{|c|c|c|c|c|}
\hline Abnormality on US & $\begin{array}{l}\text { Reference standard used } \\
\text { for comparison }\end{array}$ & $\begin{array}{c}N \text { studies } \\
\text { (N patients) }\end{array}$ & $\begin{array}{l}\text { Sensitivity } \\
\text { (95\% CI) }\end{array}$ & $\begin{array}{l}\text { Specificity } \\
(95 \% \mathrm{CI})\end{array}$ \\
\hline \multicolumn{5}{|l|}{ Karassa et al. 2005 [62] } \\
\hline Halo sign & $\mathrm{TAB}$ & $14(532)$ & $69(57,79)$ & $82(75,87)$ \\
\hline Stenosis or occlusion & $\mathrm{TAB}$ & $15(813)$ & $68(49,82)$ & $77(65,85)$ \\
\hline Halo sign, stenosis or occlusion & $\mathrm{TAB}$ & 7 (332) & $88(74,95)$ & $78(71,84)$ \\
\hline Halo sign & ACR criteria & 7 (1092) & $55(36,73)$ & $94(82,98)$ \\
\hline Stenosis or occlusion & ACR criteria & $4(933)$ & $66(32,89)$ & $95(78,99)$ \\
\hline Halo sign, stenosis or occlusion & ACR criteria & $3(853)$ & $87(80,91)$ & $96(89,98)$ \\
\hline \multicolumn{5}{|l|}{ Arida et al. 2010 [63] } \\
\hline Unilateral halo sign & ACR criteria & $8(575)$ & $68(61,74)$ & $91(88,94)$ \\
\hline Bilateral halo sign & ACR criteria & $4(380)$ & 43 (NR) & 100 (NR) \\
\hline \multicolumn{5}{|l|}{ Ball et al. 2010 [3] } \\
\hline Halo sign & $\mathrm{TAB}$ & $9(357)$ & $75(67,82)$ & $83(78,88)$ \\
\hline Halo sign, stenosis or occlusion & $\mathrm{TAB}$ & $9(397)$ & $83(77,89)$ & $82(77,87)$ \\
\hline Halo sign & ACR criteria & $6(401)$ & $69(60,77)$ & $89(84,92)$ \\
\hline Halo sign, stenosis or occlusion & ACR criteria & $7(571)$ & $78(72,84)$ & $88(84,91)$ \\
\hline Halo sign, stenosis or occlusion & $\begin{array}{l}\text { TAB and/or ACR criteria } \\
\text { (no steroids before imaging) }\end{array}$ & $5(237)$ & $75(65,84)$ & $88(82,93)$ \\
\hline Halo sign, stenosis or occlusion & $\begin{array}{l}\text { TAB and/or ACR criteria } \\
\text { (steroids before imaging) }\end{array}$ & $7(492)$ & $72(65,79)$ & $87(82,90)$ \\
\hline \multicolumn{5}{|l|}{ Duftner et al. 2018 [64] } \\
\hline Halo sign & Clinical diagnosis & $8(605)$ & $77(62,87)$ & $96(85,99)$ \\
\hline Halo sign, stenosis or occlusion & Clinical diagnosis & $3(560)$ & $78(57,90)$ & $89(78,95)$ \\
\hline Compression sign & Clinical diagnosis & $2(140)$ & a & a \\
\hline Halo sign & TAB & $7(289)$ & $70(56,81)$ & $84(73,91)$ \\
\hline Halo sign or stenosis & $\mathrm{TAB}$ & $2(50)$ & $77(23,97)$ & $91(75,97)$ \\
\hline Halo sign, stenosis or occlusion & $\mathrm{TAB}$ & $5(611)$ & $78(48,93)$ & $91(70,98)$ \\
\hline \multicolumn{5}{|l|}{ Rinagel et al. 2019 [65] } \\
\hline Halo sign & $\mathrm{TAB}$ & $20(1096)$ & $68(57,78)$ & $81(75,86)$ \\
\hline Halo sign, stenosis or occlusion & TAB & $11(1061)$ & $78(64,87)$ & $79(73,85)$ \\
\hline
\end{tabular}

aModel failed to converge. The same research group published both studies having five patients in common; sensitivities and specificities reported were $77-79 \%$ and $100 \%$, respectively. Clinical diagnosis: final diagnosis made according to the ACR criteria or physician diagnosis; NR: not reported; TAB: temporal artery biopsy.

approach to patients with suspected GCA, providing clinical and ultrasonographic evaluation within $24 \mathrm{~h}$, can reduce the rate of permanent visual loss compared with conventional referral [72, 73], as well as avoiding unnecessary use of high-dose GCs in patient who do not have GCA.

US of the temporal \pm axillary arteries is recommended by the EULAR as the first imaging modality in patients suspected to have predominantly cranial GCA. Extracranial US may be used to diagnose LV-GCA, but is of limited value to assess the aorta [15]. In comparison with TAB, US has the advantage of being a more accessible and safer procedure, with the ability to assess several arterial territories at the same evaluation, provide immediate results to the clinician and be repeated in cases of suspected disease activity [74]. However, it is operator and machine dependent, and the final ultrasonographic diagnosis of GCA is highly dependent upon the presence or absence of the halo sign in any arterial segment assessed. Like in other diseases (e.g. RA [75]), an ultrasonographic scoring system is needed to improve GCA assessment. In 2014, a semi-quantitative score, based on the extent and severity of the halo sign in temporal and axillary arteries, was proposed by Brier et al. [76]. Recently, Monti and colleagues developed a quantitative score, combining ultrasonographic findings (maximum intima-media thickness and bilaterality of the halo sign at the level of the temporal and axillary arteries) and clinical features of the disease (ischaemic symptoms, elevated CRP or ESR and presence of $\mathrm{PMR}$ ), to stratify patients according to the risk of having a positive $T A B$, supporting the use of US as a surrogate for TAB [77].

Very-high resolution US (frequency $55 \mathrm{MHz}$, axial resolution $0.045 \mathrm{~mm}$ ) has recently been reported to provide improved assessment of the temporal arteries, with superior distinction of the intima, media and adventitia layers, compared with conventional US (frequencies $<25 \mathrm{MHz}$ ), in patients with GCA [78]. It is expected that in the near future, with advances in technology and widespread use of improved US machines, research conducted with very-high resolution US will increase, as well as the reported sensitivity and specificity of US to diagnose GCA. 


\section{Other imaging modalities}

In patients with predominantly cranial GCA, highresolution $\mathrm{MRI}$ of the scalp arteries may be used as an alternative diagnostic modality for GCA, particularly if US is not available or US results are not conclusive [15]. Several studies, using 1.5-T and 3-T MRI scanners, have assessed the diagnostic value of wall thickening and contrast enhancement in the temporal, occipital and intracranial arteries of patients with suspected GCA [79-86]. A meta-analysis comparing MRI with TAB and clinical diagnosis of GCA reported a pooled sensitivity and specificity of $93 \%(95 \% \mathrm{Cl} 89,96 \%)$ and $81 \%(95 \% \mathrm{Cl} 73,81 \%)$, and of $73 \%(95 \% \mathrm{Cl} 57,85 \%)$ and $88 \%(95 \% \mathrm{Cl} 81$, $92 \%)$, respectively [64]. Normal MRI of the cranial arteries has been strongly associated with a normal TAB, with a negative predictive value of $98 \%$ [86]. Therefore, it has been proposed that MRI could be used as the initial diagnostic tool, with TAB being reserved only for cases with abnormal MRI results. However, MRI should be performed within the first 5 days of GC initiation in order to avoid decrease in sensitivity [83], which may not feasible in many centres. In addition, the high cost of MRI, the necessary expertise required in the interpretation of results and patients' potential adverse reactions to contrast agents or claustrophobia may further restrict the widespread use of this diagnostic modality. Recently, Goll et al. [87] have explored the use of 7-T cranial MRI in three patients with GCA, reporting improved image quality with detailed visualization of the vasculitic changes, in comparison with 3-T cranial MRI. Thus, like with US, ongoing technological progress may improve the diagnostic performance of cranial MRI in the future.

In the latest EULAR guidelines for the use of imaging in large-vessel vasculitis, CT and PET were not recommended for the evaluation of cranial GCA [15], mainly due to insufficient spatial resolution of these imaging modalities and high fluorodeoxyglucose (FDG) uptake in the brain during PET obscuring the assessment of temporal arteries. However, a recent retrospective case-control study, including a small number of patients with the diagnosis of GCA $(n=14)$, identified temporal artery abnormalities on cranial CT angiography suggestive of the disease, particularly blurred vessel wall margins and perivascular enhancement, yielding a sensitivity of $71 \%$ $(95 \% \mathrm{Cl} 42,92 \%)$ and a specificity of $86 \%(95 \% \mathrm{Cl} 57$, 98\%) when compared with clinical diagnosis [88]. In addition, recent reports with newer generation PET-CT scanners have demonstrated the detection of vasculitis in the temporal, occipital, maxillary and vertebral arteries [8994]. Therefore, as research in this area continues to evolve, CT and PET may be incorporated into future recommendations for diagnostic assessment of cranial GCA.

When there is a clinical suspicion of LV-GCA, imaging assessment of the extra-cranial arteries should be considered. The diagnostic procedure of choice is still unclear and mainly based on local settings and expertise. US, MRI, CT and/or PET may be used; conventional angiography has been superseded and is currently considered only to be of historical interest in the diagnosis of
GCA [15]. MRI has an important role in the detection of early signs of vasculitis, particularly wall thickness and enhancement, before arterial complications occur; however, dissociation between inflammatory markers, or clinically defined disease activity, and presence of mural contrast enhancement has been described, potentially as a result of vascular remodelling and persistence of neovessels [9597]. As in cranial-GCA, diagnostic sensitivity of MRI for LVGCA has been reported to rapidly reduce after 5 days of GC treatment [98]. CT is useful to visualize mural thickening, but has the disadvantage of exposing patients to ionizing radiation [99]. Lariviere et al. reported a sensitivity of $73 \%(95 \% \mathrm{Cl} 45,92 \%)$ and a specificity of $78 \%(95 \% \mathrm{Cl}$ $40,97 \%)$ to diagnose GCA with this imaging modality [100]. Both MRI and CT can detect structural lesions, such as stenosis, occlusions and aneurysms; however, CT is more accessible and enables better spatial resolution, and image acquisition takes less time in comparison with MRI [101]. ${ }^{18} \mathrm{~F}-\mathrm{FDG}-\mathrm{PET}$ is useful to evaluate the presence of LV-GCA, with a higher sensitivity for early vascular inflammation when compared with MRI or CT [100, 102]. In addition, identification of distinct distribution patterns of FDG uptake (e.g. in shoulders, hips and spinous processes) can contribute to the diagnosis of concomitant PMR [103, 104]. The combination of PET with CT improves the identification of anatomic areas and the differential diagnosis with atherosclerosis (Fig. 3). Different methods (e.g. visual or semiquantitative) have been used to define the presence of vascular inflammation in FDG-PET. Grading of vascular uptake based on liver uptake appears to provide a high degree of diagnostic accuracy $[105,106]$. Two meta-analyses looking at the diagnostic performance of PET or PET-CT specifically in patients with GCA reported a pooled sensitivity of $80 \%$ (95\% Cl 63, 91\%) and 90\% (95\% Cl 79, 96\%), and a pooled specificity of $89 \%(95 \% \mathrm{Cl} 78,94 \%)$ and $98 \%$

FIG. 3 PET-CT of a patient with LV-GCA showing vascular uptake (aorta and subclavian and axillary arteries)

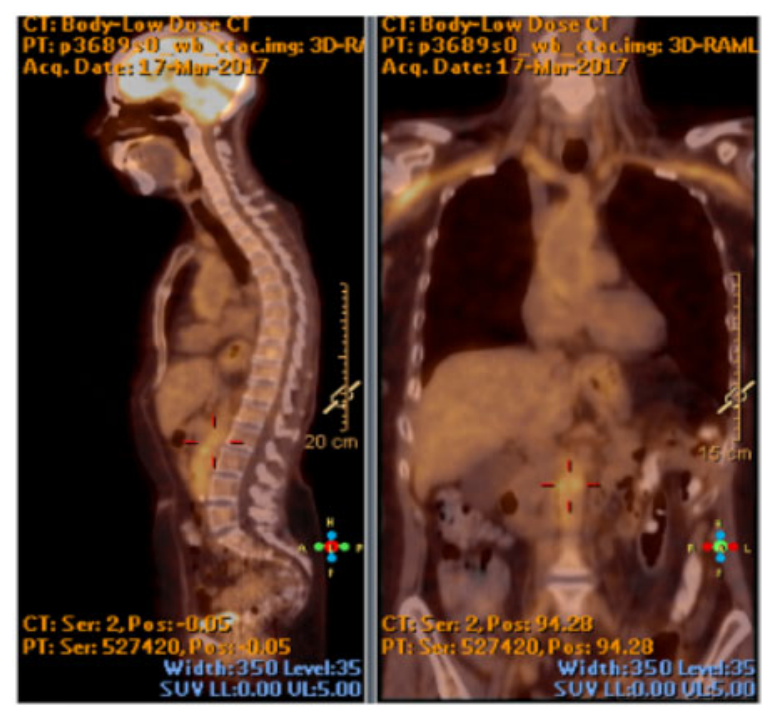

LV-GCA: large-vessel GCA. 
(95\% Cl 94, 99\%), respectively [106, 107]. One of the major advantages of PET is the ability to identify alternative diagnoses, such as infection or malignancy. This can be particularly useful in patients with PMR and poor response to standard doses of GCs, where underlying malignancy or GCA is suspected, or in patients that present with unexplained constitutional symptoms and high levels of inflammatory markers, without any specific feature of GCA, in whom a correct differential diagnosis is essential. The diagnostic performance of PET has been reported to remain unchanged within the first 3 days of GC treatment, but with a significant decrease after 10 days of GCs [108]. In many centres it is difficult to perform this examination at short notice; PET will therefore not be a good option if patients also have cranial features of the disease (where treatment cannot be delayed or withdrawn due to possible ischaemic complications). Other limitations of PET include high costs and exposure to radiation. In addition, blood glucose levels should be $<7 \mathrm{mmol} / \mathrm{l}(126 \mathrm{mg} / \mathrm{dl})$ for good sensitivity [15].

\section{Diagnostic and classification criteria}

There are no diagnostic criteria for GCA. Classification criteria were developed in 1990 , by the ACR, with a positive threshold of three out of five criteria (age $>50$ years, headache, temporal artery abnormality on examination, high ESR and abnormal TAB) [109]. However, these criteria were designed to differentiate GCA from other vasculitides, not from non-vasculitic diseases, and therefore are not suitable for diagnosis and have been reported to perform poorly when applied to this effect [110]. In addition, the 1990 ACR criteria were established before the widespread use of advanced vascular imaging modalities, only took into account cranial features of the disease and followed the "number of criteria' rule, in which each criterion had equal weight as a classifier despite its importance. Therefore, between January 2011 and December 2017, a multinational, observational study, with the aim of developing diagnostic criteria and update classification criteria for systemic vasculitis, was conducted: The Diagnostic and Classification Criteria for Vasculitis study [111]. Draft revised classification criteria for GCA have already been presented [112]. They consisted of differently weighted criteria with a threshold score, and included typical clinical symptoms of GCA, abnormalities on temporal artery examination, high levels of inflammatory markers, abnormal $T A B$ and specific patterns of imaging findings (including temporal artery halo on US or FDG-PET activity throughout the aorta). Full publication is expected soon.

\section{A proposed diagnostic approach}

As discussed previously, in case of suspected GCA, treatment should be started promptly to prevent the occurrence of ischaemic complications, such as blindness. However, it is crucial to ensure correct diagnosis to avoid overtreatment. Many discussions on whether imaging, particularly US, is an appropriate surrogate for $\mathrm{TAB}$ in the diagnosis of GCA have taken place, particularly in the last decade $[113,114]$. Despite TAB's many limitations already highlighted (low sensitivity for diagnosis, disagreement between pathologists, lack of immediate results, etc.) it is still considered by the majority of the scientific community to be the diagnostic "gold standard' for GCA. Our opinion is that imaging and TAB are complementary, and in a setting where imaging is readily available with correct expertise, it should be the first modality of choice to diagnose GCA, given the prompt availability of the results, possibility to evaluate other potential vasculitic arteries and non-invasive assessment of patients at low cost. This is also supported by the recent EULAR recommendations on the use of imaging in large-vessel vasculitis [15] and the EULAR guidelines on management of large vessel vasculitis [115].

When the initial suspicion is of cranial-GCA, US of the temporal \pm axillary arteries should be the first imaging modality. Cranial MRI could be an alternative, but is restricted to few centres with expertise on this imaging technique and that can support its high costs. In cases of positive US, if the patient already has a high clinical suspicion of GCA (e.g. jaw claudication, anterior ischaemic optic neuropathy, high inflammatory marker levels, etc.), the diagnosis of GCA can be established without further testing (TAB or subsequent imaging) $[15,116]$. In cases of positive US, but with low to medium clinical suspicion of GCA (e.g. unspecific headache, age $<60$ years, low inflammatory marker levels, etc.) and where other more obvious diagnoses have been excluded (e.g. ANCA-associated vasculitis, malignancy, etc. [117]), the authors advise a critical review of the imaging results. It is important to consider if the examination was performed by an experienced ultrasonographer (usually considered as such if $>300$ vascular examinations have been previously performed), and whether the halo sign was found bilaterally, in many artery branches and with a high maximum intima-media thickness [63, 77, 118]. If there is strong ultrasonographic evidence of GCA, the authors propose that further testing is unnecessary to confirm the diagnosis. However, if the US results appear to be less certain, TAB should be performed (or cranial MRI, depending on the setting). On the other hand, in cases of negative US, if the patient has a low clinical suspicion of GCA, no further testing is necessary to exclude GCA and an alternative diagnosis should be sought $[15,116]$. However, in cases of negative US, but with medium to high clinical suspicion of GCA, the authors advise further review the imaging results and additional efforts to safely exclude GCA (e.g. TAB or further imaging). This is particularly important for cases of GCA where inflammation in TAB is restricted to the vasa vasorum or peri-adventitial small vessels, in which the frequency of positive US has been reported to be significantly lower compared with those with classic transmural inflammation in $\operatorname{TAB}[40,119]$. 
In addition, it is important to remember that in the majority of studies the specificity of US was higher than its sensitivity to diagnose GCA; therefore, we can more comfortably diagnose GCA based on a positive US test, than exclude this disease based on a negative examination. A proposed algorithm to diagnose cranial-GCA in centres with rapid access to high-quality US can be seen in Fig. 4. In centres where imaging is not readily available and TAB is performed rapidly and with a high level of expertise, one may consider adapting the proposed algorithm, placing TAB as the first test; however, given the low sensitivity of histology reported in the diagnosis of GCA (39\% in the TABUL study [29]), in case of negative TAB, we advise looking for further ways to safely exclude GCA (e.g. imaging), regardless of the pre-test probability.

For patients in whom a diagnosis of LV-GCA is suspected, the diagnostic approach will depend on local expertise and imaging availability. In addition, patients with LV-GCA may or may not have cranial features of the disease; therefore, if cranial involvement is present, the initial diagnostic approach should follow the same principles as described for cranial-GCA. In cases of suspected LV-GCA without cranial manifestations (e.g. patients with PMR non-responders to standard doses of GCs, presenting with constitutional features, high inflammatory marker levels or abnormalities in peripheral pulses), patients should undergo imaging. US would be the first imaging modality of choice for many centres with high expertise in this technique, particularly given its low cost and generally rapid access. US can reliably assess axillary arteries, which are very frequently involved in GCA [17, 120, 121]; however, it is of limited use to evaluate the thoracic aorta, another commonly involved arterial segment in GCA [122]. If US is negative, MRI, CT or PET can be used; although PET seems to be the most sensitive examination to assess inflammation, it has the disadvantage of rapidly decreasing its sensitivity for diagnosis after 3 days of steroids [108], making it unfeasible to perform in many centres. The question remains in cases where US is positive for LVGCA: should another subsequent imaging modality be performed specifically to evaluate the thoracic aorta? Blockmans et al. reported that patients with GCA who had increased FDG uptake in the aorta during the acute phase of the disease were more prone to develop thoracic aortic dilatation during late follow-up [123] However, there are no current recommendations regarding the need for screening the aorta at baseline after the diagnosis of GCA as already been established [15].

\section{Conclusion}

The evaluation of a patient with suspected GCA should be performed quickly in order to avoid potential ischaemic complications, such as visual loss. The clinician must investigate all the features of the disease, bearing in mind the high specificity for GCA of some of the less common clinical features such as jaw claudication or arteritic anterior ischaemic optic neuropathy. Further investigation should not delay treatment initiation.

Clinicians should make all efforts to confirm the diagnosis of GCA. The current cheapest, fastest and safest way to diagnose GCA in many centres is by performing US, and depending on the clinical setting this diagnostic modality may preclude the need for TAB. Imaging will

\section{FIG. 4 A proposed algorithm to diagnose cranial-GCA in centres with rapid access to high quality US}

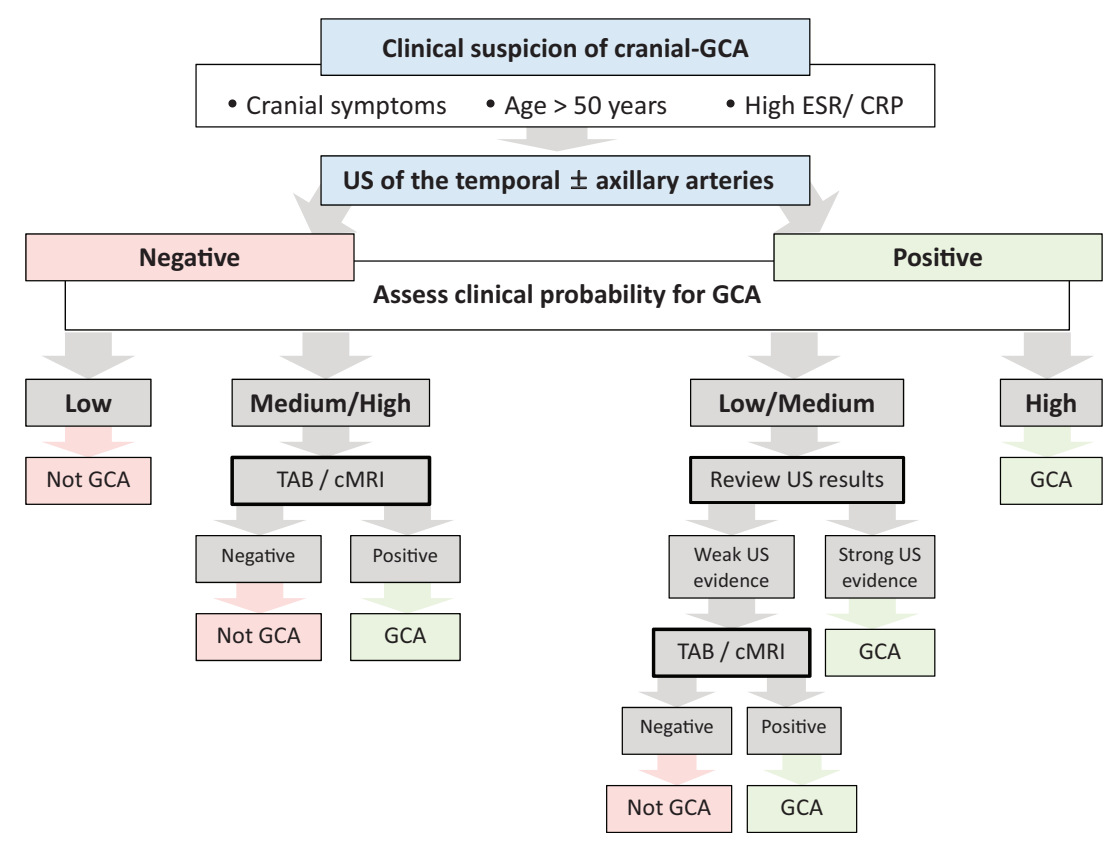

cMRI: cranial MRI; TAB: temporal artery biopsy. 
be part of the new classification criteria for GCA and will likely play an increasingly significant role in the assessment of these patients at onset and over the course of their disease. As technology evolves, newer generation PET-CT machines, very-high resolution US probes, and superior MRI and CT scanners will improve the diagnostic performance of imaging. The challenge will then be to balance the benefit of their use with the associated costs.

Although there are currently many diagnostic tests available, a personalized approach to the diagnosis of GCA based on clinical manifestations, accessible modalities and expertise should ultimately be the clinician's goal in daily practice.

Funding: No specific funding was received from any funding bodies in the public, commercial or not-forprofit sectors to carry out the work described in this manuscript. This paper forms part of the supplement entitled EUVAS Cambridge Vasculitis Course 2019. This supplement was supported by University of Cambridge.

Disclosure statement: The authors have declared no conflicts of interest.

\section{References}

1 Kale N, Eggenberger E. Diagnosis and management of giant cell arteritis: a review. Curr Opin Ophthalmol 2010;21:417-22.

2 Ponte C, Águeda AF, Luqmani RA. Clinical features and structured clinical evaluation of vasculitis. Best Pract Res Clin Rheumatol 2018;32:31-51.

3 Ball EL, Walsh SR, Tang TY, Gohil R, Clarke J. Role of ultrasonography in the diagnosis of temporal arteritis. Br J Surg 2010;97:1765-71.

4 Jennette JC, Falk RJ, Bacon PA et al. 2012 revised international Chapel Hill consensus conference nomenclature of vasculitides. Arthritis Rheum 2013;65:1-11.

5 Proven A, Gabriel SE, Orces C, O'Fallon WM, Hunder GG. Glucocorticoid therapy in giant cell arteritis: duration and adverse outcomes. Arthritis Rheum 2003;49:703-8.

6 Wilson JC, Sarsour K, Collinson N et al. Serious adverse effects associated with glucocorticoid therapy in patients with giant cell arteritis (GCA): a nested casecontrol analysis. Semin Arthritis Rheum 2017;46: 819-27.

7 Smith JH, Swanson JW. Giant cell arteritis. Headache 2014;54:1273-89.

8 Peral-Cagigal B, Pérez-Villar Á, Redondo-González $\mathrm{LM}$ et al. Temporal headache and jaw claudication may be the key for the diagnosis of giant cell arteritis. Med Oral Patol Oral Cir Bucal 2018;23:e290-4.

9 Salvarani C, Cimino L, Macchioni $\mathrm{P}$ et al. Risk factors for visual loss in an Italian population-based cohort of patients with giant cell arteritis. Arthritis Rheum 2005; 53:293-7.

10 González-Gay MA, García-Porrúa C, Llorca J et al. Visual manifestations of giant cell arteritis. Trends and clinical spectrum in 161 patients. Medicine (Baltimore) 2000;79:283-92.

11 Caselli RJ, Hunder GG, Whisnant JP. Neurologic disease in biopsy-proven giant cell (temporal) arteritis. Neurology 1988;38:352-9.

12 Nesher G, Berkun $\mathrm{Y}$, Mates $\mathrm{M}$ et al. Risk factors for cranial ischemic complications in giant cell arteritis. Medicine 2004;83:114-22.

13 Gonzalez-Gay MA, Vazquez-Rodriguez TR, GomezAcebo l et al. Strokes at time of disease diagnosis in a series of 287 patients with biopsy-proven giant cell arteritis. Medicine 2009;88:227-35.

14 Dasgupta B; Giant Cell Arteritis Guideline Development Group. Concise guidance: diagnosis and management of giant cell arteritis. Clin Med (Lond) 2010;10:381-6.

15 Dejaco C, Ramiro S, Duftner C et al. EULAR recommendations for the use of imaging in large vessel vasculitis in clinical practice. Ann Rheum Dis 2018;77: 636-43.

16 Blockmans D, de Ceuninck L, Vanderschueren S et al. Repetitive 18F-fluorodeoxyglucose positron emission tomography in giant cell arteritis: a prospective study of 35 patients. Arthritis Rheum 2006; 55:131-7.

17 Schmidt WA, Seifert A, Gromnica-Ihle E, Krause A, Natusch A. Ultrasound of proximal upper extremity arteries to increase the diagnostic yield in large-vessel giant cell arteritis. Rheumatology (Oxford) 2008;47: 96-101.

18 García-Martínez A, Hernández-Rodríguez J, Arguis P et al. Development of aortic aneurysm/dilatation during the followup of patients with giant cell arteritis: a crosssectional screening of fifty-four prospectively followed patients. Arthritis Rheum 2008;59:422-30.

19 Muratore F, Kermani TA, Crowson CS et al. Largevessel giant cell arteritis: a cohort study. Rheumatol (Oxford) 2015;54:463-70.

20 Nuenninghoff DM, Hunder GG, Christianson TJ, McClelland RL, Matteson EL. Incidence and predictors of large-artery complication (aortic aneurysm, aortic dissection, and/or large-artery stenosis) in patients with giant cell arteritis: a population-based study over 50 years. Arthritis Rheum 2003;48:3522-31.

21 Robson JC, Kiran A, Maskell $\mathrm{J}$ et al. The relative risk of aortic aneurysm in patients with giant cell arteritis compared with the general population of the UK. Ann Rheum Dis 2015;74:129-35.

22 Bienvenu B, Ly KH, Lambert $\mathrm{M}$ et al. Management of giant cell arteritis: recommendations of the French Study Group for Large Vessel Vasculitis (GEFA). Rev Med Interne 2016;37:154-65.

23 Dejaco C, Brouwer E, Mason JC et al. Giant cell arteritis and polymyalgia rheumatica: current challenges and opportunities. Nat Rev Rheumatol 2017;13:578-92.

24 Hayreh SS, Podhajsky PA, Zimmerman B. Occult giant cell arteritis: ocular manifestations. Am J Opthalmol 1998;125:521-6.

25 Cid MC, Font C, Oristrell $\mathrm{J}$ et al. Association between strong inflammatory response and low risk of 
developing visual loss and other cranial ischaemic complications in giant cell (temporal arteritis). Arthritis Rheum 1998;41:26-32.

26 Salvarani C, Bella CD, Cimino L et al. Risk factors for severe cranial ischaemic events in an Italian populationbased cohort of patients with giant cell arteritis. Rheumatology (Oxford) 2008;48:250-3.

27 Amor-Dorado JC, Llorca J, Garcia-Porrua C et al. Audiovestibular manifestations in giant cell arteritis: a prospective study. Medicine (Baltimore) 2003;82:13-26.

28 Hayreh SS, Zimmerman B, Kardon RH. Visual improvement with corticosteroid therapy in giant cell arteritis. Report of a large study and review of literature. Acta Ophthalmol Scand 2002;80:355-67. Erratum in: Acta Ophthalmol Scand 2002; 80: 688.

29 Luqmani R, Lee E, Singh S et al. The Role of Ultrasound Compared to Biopsy of Temporal Arteries in the Diagnosis and Treatment of Giant Cell Arteritis (TABUL): a diagnostic accuracy and cost-effectiveness study. Health Technol Assess 2016;20:1-238.

30 Breuer GS, Nesher R, Nesher G. Effect of biopsy length on the rate of positive temporal artery biopsies. Clin Exp Rheumatol 2009;27:S10-3.

31 Ypsilantis E, Courtney ED, Chopra $\mathrm{N}$ et al. Importance of specimen length during temporal artery biopsy. Br J Surg 2011;98:1556-60.

32 Mahr A, Saba M, Kambouchner M et al. Temporal artery biopsy for diagnosing giant cell arteritis: the longer, the better? Ann Rheum Dis 2006;65:826-8.

33 Taylor-Gjevre R, Vo M, Shukla D, Resch L. Temporal artery biopsy for giant cell arteritis. J Rheumatol 2005; 32:1279-82.

34 Germano G, Muratore F, Cimino L et al. Is colour duplex sonography-guided temporal artery biopsy useful in the diagnosis of giant cell arteritis? A randomized study. Rheumatology (Oxford) 2015;54:400-4.

35 Hall S, Hunder GG. Is temporal artery biopsy prudent? Mayo Clin Proc 1984;59:793-6.

36 Ponge T, Barrier JH, Grolleau JY et al. The efficacy of selective unilateral temporal artery biopsy versus bilateral biopsies for diagnosis of giant cell arteritis. J Rheumatol 1988;15:997-1000.

37 Gonzalez -Gay MA, Alonso MD, Aguero JJ et al. Temporal arteritis in a northwestern area of Spain: study of 57 biopsy proven patients. J Rheumatol 1992; 19:277-80.

38 Boyev LR, Miller NR, Green WR. Efficacy of unilateral versus bilateral temporal artery biopsies for the diagnosis of giant cell arteritis. Am J Ophthalmol 1999; 128:211-5.

39 Breuer GS, Nesher G, Nesher R. Rate of discordant findings in bilateral temporal artery biopsy to diagnose giant cell arteritis. J Rheumatol 2009;36:794-6.

40 Cavazza A, Muratore F, Boiardi L et al. Inflamed temporal artery: histologic findings in 354 biopsies, with clinical correlations. Am J Surg Pathol 2014;38:1360-70.

41 Jia L, Couce M, Barnholtz-Sloan JS, Cohen ML. Is all inflammation within temporal artery biopsies temporal arteritis? Hum Pathol 2016;57:17-21.
42 Muratore F, Boiardi L, Cavazza A et al. Correlations between histopathological findings and clinical manifestations in biopsy-proven giant cell arteritis. J Autoimmun 2016;69:94-101.

43 Macchioni $\mathrm{P}$, Boiardi L, Muratore $\mathrm{F}$ et al. Survival predictors in biopsy-proven giant cell arteritis: a northern Italian population-based study. Rheumatology (Oxford) 2019;58:609-16.

44 Stacy RC, Rizzo JF, Cestari DM. Subtleties in the histopathology of giant cell arteritis. Semin Ophthalmol 2011;26:342-8.

45 Restuccia G, Cavazza A, Boiardi L et al. Small-vessel vasculitis surrounding an uninflamed temporal artery and isolated vasa vasorum vasculitis of the temporal artery: two subsets of giant cell arteritis. Arthritis Rheum 2012;64:549-56.

46 Le Pendu C, Meignin V, Gonzalez-Chiappe S et al. Poor predictive value of isolated adventitial and periadventitial infiltrates in temporal artery biopsies for diagnosis of giant cell arteritis. J Rheumatol 2017;44:1039-43.

47 Klein RG, Campbell RJ, Hunder GG, Carney JA. Skip lesions in temporal arteritis. Mayo Clin Proc 1976; 51:504-10.

48 Brack A, Martinez-Taboada V, Stanson A, Goronzy JJ, Weyand CM. Disease pattern in cranial and largevessel giant cell arteritis. Arthritis Rheum 1999;42:311-7.

49 Ikard RW. Clinical efficacy of temporal artery biopsy in Nashville, Tennessee. South Med J 1988;81:1222-4.

50 Slavin ML. Brow droop after superficial temporal artery biopsy [Letter]. Arch Ophthalmol 1986;104:1127.

51 Bhatti MT, Taher RM. Partial facial paralysis following temporal artery biopsy. Eye 2000;14:918-9.

52 Bhatti MT, Goldstein MH. Facial nerve injury following superficial temporal artery biopsy. Dermatol Surg 2001; 27:15-7.

53 Yoon MK, Horton JC, McCulley TJ. Facial nerve injury: a complication of superficial temporal artery biopsy. Am J Ophthalmol 2011;152:251-5.

54 Rison RA. Branch facial nerve trauma after superficial temporal artery biopsy: a case report. J Med Case Rep 2011;5:34.

55 Murchison AP, Bilyk JR. Brow ptosis after temporal artery biopsy: incidence and associations. Ophthalmology 2012;119:2637-42.

56 Siemssen SJ. On the occurrence of necrotising lesions in arteritis temporalis: review of the literature with a note on the potential risk of a biopsy. Br J Plast Surg 1987;40:73-82.

57 Schmidt WA, Kraft HE, Vorpahl K, Völker L, GromnicaIhle EJ. Color duplex ultrasonography in the diagnosis of temporal arteritis. N Engl J Med 1997;337:1336-42.

58 Chrysidis S, Duftner C, Dejaco C et al. Definitions and reliability assessment of elementary ultrasound lesions in giant cell arteritis: a study from the OMERACT Large Vessel Vasculitis Ultrasound Working Group. RMD Open 2018;4:e000598.

59 Aschwanden M, Daikeler T, Kesten F et al. Temporal artery compression sign-a novel ultrasound finding for 
the diagnosis of giant cell arteritis. Ultraschall Med 2013;34:47-50.

60 Aschwanden M, Imfeld S, Staub D et al. The ultrasound compression sign to diagnose temporal giant cell arteritis shows an excellent interobserver agreement. Clin Exp Rheumatol 2015;33:S113-5.

61 Buttgereit F, Dejaco C, Matteson EL, Dasgupta B. Polymyalgia rheumatica and giant cell arteritis: a systematic review. JAMA 2016;315:2442-58.

62 Karassa FB, Matsagas MI, Schmidt WA, loannidis JP. Meta-analysis: test performance of ultrasonography for giant-cell arteritis. Ann Intern Med 2005;142:359-69.

63 Arida A, Kyprianou N, Kanakis M, Sfikakis PP. The diagnostic value of ultrasonography-derived edema of the temporal artery wall in giant cell arteritis: a second meta-analysis. BMC Musculoskelet Disord 2010;11:44.

64 Duftner C, Dejaco C, Sepriano A et al. Imaging in diagnosis, outcome prediction and monitoring of large vessel vasculitis: a systematic literature review and meta-analysis informing the EULAR recommendations. RMD Open 2018;4:e000612.

65 Rinagel M, Chatelus E, Jousse-Joulin S et al. Diagnostic performance of temporal artery ultrasound for the diagnosis of giant cell arteritis: a systematic review and meta-analysis of the literature. Autoimmun Rev 2019;18:56-61.

66 Polido-Pereira J, Serra S, Teixeira F et al. Portuguese recommendations for the use of ultrasound in rheumatology. Acta Reumatol Port 2019;44:7-28.

67 Schäfer VS, Juche A, Ramiro S, Krause A, Schmidt WA. Ultrasound cut-off values for intima-media thickness of temporal, facial and axillary arteries in giant cell arteritis. Rheumatology (Oxford) 2017;56:1479-83.

68 Hauenstein C, Reinhard M, Geiger J et al. Effects of early corticosteroid treatment on magnetic resonance imaging and ultrasonography findings in giant cell arteritis. Rheumatology (Oxford) 2012;51:1999-2003.

69 Karahaliou M, Vaiopoulos G, Papaspyrou S et al. Colour duplex sonography of temporal arteries before decision for biopsy: a prospective study in 55 patients with suspected giant cell arteritis. Arthritis Res Ther 2006;8:R116.

70 De Miguel E, Roxo A, Castillo $\mathrm{C}$ et al. The utility and sensitivity of colour Doppler ultrasound in monitoring changes in giant cell arteritis. Clin Exp Rheum 2012;30: S34-8.

71 Habib HM, Essa AA, Hassan AA. Color duplex ultrasonography of temporal arteries: role in diagnosis and follow-up of suspected cases of temporal arteritis. Clin Rheumatol 2012;31:231-7.

72 Patil P, Williams M, Maw WW et al. Fast track pathway reduces sight loss in giant cell arteritis: results of a longitudinal observational cohort study. Clin Exp Rheumatol 2015;33:S-103-6.

73 Diamantopoulos AP, Haugeberg G, Lindland A, Myklebust $G$. The fast-track ultrasound clinic for early diagnosis of giant cell arteritis significantly reduces permanent visual impairment: towards a more effective strategy to improve clinical outcome in giant cell arteritis? Rheumatology (Oxford) 2016;55:66-70.
74 Monti S, Floris A, Ponte C, Schmidt WA et al. The use of ultrasound to assess giant cell arteritis: review of the current evidence and practical guide for the rheumatologist. Rheumatology (Oxford) 2018;57:227-35.

75 D’Agostino MA, Terslev L, Aegerter $\mathrm{P}$ et al. Scoring ultrasound synovitis in rheumatoid arthritis: a EULAR-OMERACT ultrasound taskforce-Part 1: definition and development of a standardised, consensus-based scoring system. RMD Open 2017; 3:e000428.

76 Brier R, Borg FA, Patil P, Dejaco C, Dasgupta B. Association between temporal artery ultrasound "halo score" and biopsy in newly diagnosed giant cell arteritis. Ann Rheum Dis 2014;73:697.1.

77 Monti S, Ponte C, Pereira C et al. The impact of disease extent and severity detected by quantitative ultrasound analysis in the diagnosis and outcome of giant cell arteritis. Rheumatology 2019; doi:10.1093/ rheumatology/kez554.

78 Sundholm JKM, Paetau A, Albäck A, Pettersson T, Sarkola T. Non-invasive vascular very-high resolution ultrasound to quantify artery intima layer thickness: validation of the four-line pattern. Ultrasound Med Biol 2019;45:2010-8.

79 Bley TA, Weiben O, Uhl M et al. Assessment of the cranial involvement pattern of giant cell arteritis with 3T magnetic resonance imaging. Arthritis Rheum 2005;52: 2470-7.

80 Bley TA, Uhl M, Carew J et al. Diagnostic value of high-resolution MR imaging in giant cell arteritis. AJNR Am J Neuroradiol 2007;28:1722-7.

81 Geiger J, Bley T, Uhl M et al. Diagnostic value of T2weighted imaging for the detection of superficial cranial artery inflammation in giant cell arteritis. J Magn Reson Imaging 2010;31:470-4.

82 Franke P, Markl M, Heinzelmann $S$ et al. Evaluation of a 32-channel versus a 12-channel head coil for highresolution post-contrast MRI in giant cell arteritis (GCA) at 3T. Eur J Radiol 2014;83:1875-80.

83 Klink T, Geiger J, Both $M$ et al. Giant cell arteritis: diagnostic accuracy of MR imaging of superficial cranial arteries in initial diagnosis-results from a multicenter trial. Radiology 2014;273:844-52.

84 Veldhoen S, Klink T, Geiger J et al. MRI displays involvement of the temporalis muscle and the deep temporal artery in patients with giant cell arteritis. Eur Radiol 2014;24:2971-9.

85 Siemonsen S, Brekenfeld C, Holst B et al. 3T MRI reveals extra- and intracranial involvement in giant cell arteritis. AJNR Am J Neuroradiol 2015;36:91-7.

86 Rhéaume M, Rebello R, Pagnoux $C$ et al. Highresolution magnetic resonance imaging of scalp arteries for the diagnosis of giant cell arteritis: results of a prospective cohort study. Arthritis Rheumatol 2017;69:161-8.

87 Goll C, Thormann M, Hofmüller W et al. Feasibility study: $7 \mathrm{~T} \mathrm{MRI}$ in giant cell arteritis. Graefes Arch Clin Exp Ophthalmol 2016;254:1111-6.

88 Conway R, Smyth AE, Kavanagh RG et al. Diagnostic utility of computed tomographic angiography in giantcell arteritis. Stroke 2018;49:2233-6. 
89 Rehák Z, Szturz P, Křen L, Fojtík Z, Staníček J. Upsampling from aorta and aortic branches: pET/CT hybrid imaging identified 18FFDG hypermetabolism in inflamed temporal and occipital arteries. Clin Nucl Med 2014;39:e84-6.

90 Sammel AM, Hsiao E, Schrieber L et al. Fluorine-18 fluoro-2-deoxyglucose positron emission tomography uptake in the superficial temporal and vertebral arteries in biopsy positive giant cell arteritis. J Clin Rheumatol 2017;23:443.

91 Maestri Brittain J, Gormsen L, von Benzon E, Andersen $\mathrm{K}$. Concomitant polymyalgia rheumatica and large-vessel vasculitis visualized on 18F-FDG PET/CT. Diagnostics 2018;8:27.

92 Sammel AM, Hsiao E, Nguyen K, Schembri G, Laurent R. Maxillary artery 18F-FDG uptake as a new finding on PET/CT scan in a cohort of 41 patients suspected of having giant cell arteritis. Int $\mathrm{J}$ Rheum Dis 2018;21:560-2.

93 Sammel AM, Hsiao E, Schembri G et al. Diagnostic accuracy of PET/CT scan of the head, neck and chest for giant cell arteritis: the double-blinded giant cell arteritis and PET Scan (GAPS) study. Arthritis Rheumatol 2019;71:1319.

94 Nielsen BD, Hansen IT, Kramer S et al. Simple dichotomous assessment of cranial artery inflammation by conventional 18F-FDG PET/CT shows high accuracy for the diagnosis of giant cell arteritis: a case-control study. Eur J Nucl Med Mol Imaging 2019;46:184-93.

95 Scheel AK, Meller J, Vosshenrich R et al. Diagnosis and follow up of aortitis in the elderly. Ann Rheum Dis 2004;63:1507-10.

96 Both M, Ahmadi-Simab K, Reuter M et al. MRI and FDG-PET in the assessment of inflammatory aortic arch syndrome in complicated courses of giant cell arteritis. Ann Rheum Dis 2008;67:1030-3.

97 Reichenbach S, Adler S, Bonel $\mathrm{H}$ et al. Magnetic resonance angiography in giant cell arteritis: results of a randomized controlled trial of tocilizumab in giant cell arteritis. Rheumatology (Oxford) 2018;57:982-6.

98 Adler S, Sprecher M, Wermelinger F et al. Diagnostic value of contrast-enhanced magnetic resonance angiography in large-vessel vasculitis. Swiss Med Wkly 2017;147:w14397.

99 Prieto-González S, Arguis P, García-Martínez A et al. Large vessel involvement in biopsy-proven giant cell arteritis: prospective study in 40 newly diagnosed patients using CT angiography. Ann Rheum Dis 2012; 71:1170-6.

100 Lariviere D, Benali K, Coustet B et al. Positron emission tomography and computed tomography angiography for the diagnosis of giant cell arteritis: a real-life prospective study. Medicine (Baltimore) 2016; 95:e4146.

101 Prieto-González S, Villarreal-Compagny M, Cid MC. Usefulness of imaging techniques in the management of giant cell arteritis. Med Clin (Barc) 2019;152:495-501.

102 Meller J, Strutz F, Siefker U et al. Early diagnosis and follow-up of aortitis with [(18)F]FDG PET and MRI. Eur J Nucl Med Mol Imaging 2003;30:730-6.
103 Blockmans D, De Ceuninck L, Vanderschueren S et al. Repetitive 18-fluorodeoxyglucose positron emission tomography in isolated polymyalgia rheumatica: a prospective study in 35 patients. Rheumatology (Oxford) 2006;46:672-7.

104 Yuge S, Nakatani K, Yoshino K, Koyama T. Diagnosing polymyalgia rheumatica on 18F-FDG PET/ CT: typical uptake patterns. Ann Nucl Med 2018;32: 573-7.

105 Slart R, Glaudemans A, Chareonthaitawee $P$ et al. FDG-PET/CT(A) imaging in large vessel vasculitis and polymyalgia rheumatica: joint procedural recommendation of the EANM, SNMMI, and the PET Interest Group (PIG), and endorsed by the ASNC. Eur J Nucl Med Mol Imaging 2018;45:1250-69.

106 Soussan M, Nicolas P, Schramm C et al. Management of large-vessel vasculitis with FDG-PET: a systematic literature review and meta-analysis. Medicine (Baltimore) 2015;94:e622.

107 Besson FL, Parienti JJ, Bienvenu B et al. Diagnostic performance of $18 \mathrm{~F}$-fluorodeoxyglucose positron emission tomography in giant cell arteritis: a systematic review and meta-analysis. Eur J Nucl Med Mol Imaging 2011;38:1764-72.

108 Nielsen BD, Gormsen LC, Hansen IT et al. Three days of high-dose glucocorticoid treatment attenuates large-vessel 18F-FDG uptake in large-vessel giant cell arteritis but with a limited impact on diagnostic accuracy. Eur J Nucl Med Mol Imaging 2018;45:1119-28.

109 Hunder GG, Bloch DA, Michel BA et al. The American College of Rheumatology 1990 criteria for the classification of giant cell arteritis. Arthritis Rheum 1990;33:1122-8.

110 Seeliger B, Sznajd J, Robson JC et al. Are the 1990 American College of Rheumatology vasculitis classification criteria still valid? Rheumatology (Oxford) 2017;56:1154-61.

111 Craven A, Robson J, Ponte C et al. ACR/EULARendorsed study to develop Diagnostic and Classification Criteria for Vasculitis (DCVAS). Clin Exp Nephrol 2013;17:619-21.

112 Ponte C, Grayson P, Suppiah R et al. Classification criteria for large vessel vasculitis. Rheumatology (Oxford) 2019;58:ii32.

113 Croft A, Thompson N, Duddy M et al. OP0056 can we replace temporal artery biopsy with cranial ultrasound for the diagnosis of giant cell arteritis? A retrospective cohort study of the diagnostic utility of ultrasound in routine clinical practice. Ann Rheum Dis 2014;73:82.1.

114 Moiseev SV, Smitienko I, Bulanov N, Pavel I Novikov $\mathrm{PI}$. The role of temporal artery biopsy in patients with giant-cell arteritis is debated. Ann Rheum Dis 2019;78:e31.

115 Hellmich B, Águeda AF, Monti S et al. 2018 Update of the EULAR recommendations for the management of large vessel vasculitis. Ann Rheum Dis 2019;pii: annrheumdis-2019-215672. doi: 10.1136/annrheumdis-2019-215672.

116 Laskou F, Coath F, Mackie SL et al. A probability score to aid the diagnosis of suspected giant cell arteritis. Clin Exp Rheumatol 2019;37(Suppl 117):104-8. 
117 Fernández E, Monjo I, Bonilla G et al. OP0210 False positives of ultrasound in giant cell arteritis. Some diseases can also have halo sign. Ann Rheum Dis 2019;78:181.

118 Aranda-Valera IC, García Carazo S, Monjo Henry I, De Miguel Mendieta E. Diagnostic validity of Doppler ultrasound in giant cell arteritis. Clin Exp Rheumatol 2017;35:123-7.

119 Muratore F, Boiardi L, Restuccia G et al. Comparison between colour duplex sonography findings and different histological patterns of temporal artery. Rheumatology (Oxford) 2013;52:2268-74.

120 Grayson PC, Maksimowicz-McKinnon K, Clark TM et al. Distribution of arterial lesions in Takayasu's arteritis and giant cell arteritis. Ann Rheum Dis 2012;71: 1329-34.

121 Gribbons KB, Ponte C, Craven A et al. Comparison of arterial patterns of disease in Takayasu's arteritis and giant cell arteritis. Arthritis Care Res (Hoboken) 2019; doi: 10.1002/acr.24055.

122 Soriano A, Pazzola G, Boiardi L et al. Distribution patterns of $18 \mathrm{~F}$-fluorodeoxyglucose in large vessels of Takayasu's and giant cell arteritis using positron emission tomography. Clin Exp Rheumatol 2018;36:99-106.

123 Blockmans D, Coudyzer W, Vanderschueren S et al. Relationship between fluorodeoxyglucose uptake in the large vessels and late aortic diameter in giant cell arteritis. Rheumatology (Oxford) 2008;47:1179-84. 